\author{
DUTRA, L. H. A. - Pragmática de modelos - natureza, estrutura e uso dos \\ modelos científicos.
}

São Paulo: Edições Loyola, 2013. Páginas: 344

\title{
As concepções semântica e pragmática dos modelos científicos: revisitando o debate
}

\author{
Mariana Faria Brito Francisquini ${ }^{1}$ \\ Instituto Federal de Educação, \\ Ciência e Tecnologia do Rio de \\ Janeiro- Campus Niterói \\ marianfrancisquini@ifrj.edu.br
}

Recebido em 02/04/2017

Aceito em 09/04/2017
1 Bolsista do Programa de Pós-Graduação em Ensino de Matemática - Doutorado em Ensino e História da Matemática e da Física (UFRJ)
A importância das funções desempenhadas pelos modelos há muito é estudada na literatura. No contexto científico, os cientistas empregam muito esforço na sua construção, manipulação e revisão. Essa atenção dirigida aos modelos e aos papéis desempenhados por eles tem impulsionado a criação de muitas visões e classificações diferentes na literatura filosófica. A obra de Luiz Henrique de Araújo Dutra, Professor Titular da Universidade Federal de Santa Catarina (UFSC), revisita esta bibliografia dividindo-a em duas categorias: uma de cunho conceitual (que se preocupa com a noção de modelo) e outra de cunho histórico (que se relaciona a estudos de caso). Embora o autor reconheça o valor de estudos de caso, é nítida a predileção pela primeira. Essa, reconhecida nos trabalhos de Max Black e Mary Hesse - seguidos pela abordagem semântica de Suppe, Giere e van Fraassen, logo antes de aparecerem os trabalhos de Nancy Cartwright e Morgan e Morrison -, vai fornecer ao autor o embasamento para levar seu texto a cabo. Para os objetivos do autor, que se alinha à visão pragmática, as ideias de Cartwright, Morgan e Morrison representam posições com as quais ele irá confluir. É importante dizer que o livro não se quer introdutório (DUTRA, 2013, p.24). As ideias apresentadas ao longo da obra servem para que o autor possa introduzir o debate relativo à natureza e ao papel dos modelos na literatura para, com isso, apresentar suas próprias concepções sobre suas funções e sobre como devem ser compreendidos.

O objetivo do livro é preconizar o papel dos modelos na pesquisa científica. Neste sentido, Dutra escolhe tratá-los não como instrumentos heurísticos de teorias ou formas de relacionar teoria e fato, mas como estruturas independentes das teorias. À primeira vista, o objetivo do livro não parece oferecer contribuições muito originais, uma vez que podemos encontrar o mesmo tratamento no trabalho de Morgan e Morrison. No entanto, o autor mantém alguns traços pessoais que serão apresentados no decorrer da obra que diferem sua abordagem daquela de Morgan e Morrison. 
A obra é apresentada ao longo de dez capítulos, breve prefácio e algumas páginas introdutórias. Não há capítulo de conclusão, o que sugere que a discussão não está finalizada. A apresentação do livro é bem organizada de modo que, ao início de cada capítulo, há uma breve descrição daquilo que o leitor pode esperar encontrar nas páginas seguintes. A nosso ver, não há a necessidade de uma leitura linear - o que é certamente um atrativo aos leitores, considerando-se a extensão do livro (que ultrapassa 300 páginas). No entanto, caso a escolha seja a de uma leitura linear, acaba sendo inevitável achar algumas partes do livro prolixas uma vez que muitas informações são apresentadas exaustivamente da mesma maneira em diferentes momentos do livro.

$\mathrm{Na}$ introdução, o autor prepara o terreno para as muitas classificações de modelos com as quais o leitor terá de se deparar ao longo da obra. Sejam modelos de escala, semânticos, conjuntivos e matemáticos apenas algumas destas classificações, nem todas estas ideias representam aquilo que Dutra atribui como sendo um modelo científico. A esse respeito devemos entendê-los como estruturas abstratas que possam relacionar-se com números, proposições, figuras geométricas e instituições, sendo as discussões feitas no livro dedicadas a este tipo de modelo.

Há grande destaque no texto, também, para os papéis dos modelos. Em especial, ao interpretativo. Embora o autor tenha se baseado na obra de Cartwright para destacar as funções representativas e interpretativas destas estruturas, ele não a segue acriticamente. Não seria exagero de nossa parte dizer que o caráter interpretativo, para ele, é o que atribuiria o status de "científico" a um determinado modelo. Sem esta função, os modelos poderiam ser considerados "inúteis" ou apenas "peças decorativas de uso didático" (DUTRA, 2013, p.21) - lembrando uma posição tradicionalmente francesa sobre os modelos científicos encontrada principalmente nos trabalhos de Pierre Duhem.

Em seu capítulo primeiro é introduzida a ideia de modelos semânticos e matemáticos. Essas noções são apresentadas para chegar-se aos conceitos de modelos teóricos ou modelos-réplica que serão destacados ao longo da obra. Além disso, o autor recorre à semântica para a lógica modal alética atribuída a Kripke graças à sua noção de "mundos possíveis" para, em seguida, tratá-los como abstrações. De acordo com sua abordagem, um modelo científico idealizado tem de ser entendido como uma abstração, de modo que somente desta forma as teorias científicas podem ser entendidas (DUTRA, 2013, p.39). Embora a discussão de mundos possíveis de Kripke seja certamente interessante, devido aos exemplos empregados na obra, parece-nos desproporcional a importância dada a esta discussão. Levando-se em consideração que a ideia fundamental que permeará toda a obra é a ideia de abstração e de os modelos são estruturas abstratas, a abordagem de Dutra pode sugerir que a ideia de mundo possível seja imprescindível ao seu entendimento, em detrimento de seu caráter abstrato.

Há grande destaque também ao papel da comparação, das analogias e da metáfora na atividade de modelar. A discussão de seu segundo capítulo começa a partir das ideias de Black, principalmente aquelas relacionada à reversão da metáfora e da assimetria entre modelo e estrutura modelada. Em relação a esta última questão, Dutra não se alinha às perspectivas de Black cegamente. Para ele, se pudermos fazer uma analogia entre o uso de modelos e o de metáforas, então faz sentido supor que a analogia também possa ser reversível. Para apoiar seu argumento, exemplifica que ao compararmos homens e lobos (em referência ao famoso exemplo de Max Black) podemos conhecer algo também sobre os lobos e não apenas sobre os homens.

Na sequência do trabalho é apresentada a ideia dos modelos nômicos a partir dos trabalhos de Hempel e Nagel - ideia esta que estará presente em muitos capítulos da obra e que se relacionará com a concepção principal do autor de modelos científicos como máquinas nomológicas. Em todo o capítulo prevalece o tom de que os modelos nômicos têm um papel de maior destaque na prática do cientista, de modo que Dutra chega a referir-se a eles como sendo indispensáveis à atividade científica.

Encontramos, já no quarto capítulo, o tratamento do autor sobre a concepção semântica das teorias científicas como coleções de modelos. As críticas a dois autores desta visão, van Fraassen e Suppe, são explícitas no decorrer do capítulo. O primeiro, por seus comentários acerca dos trabalhos de Hesse e Nagel que, segundo Araújo Dutra, constituem um "exagero injustificável” (DUTRA, 2013, p.100), além de uma 
confusão terminológica relativa à sua própria concepção de modelo. O segundo, por inconsistências de sua abordagem em relação aos modelos científicos, uma vez que para o autor ele é "o autor que menos contribui para uma compreensão dos modelos científicos de modo diferente dos modelos semânticos e matemáticos" (DUTRA, 2013, p.101). Embora Dutra critique Suppe diretamente, ele reconhece que sua ideia de modelo como entidade abstrata expande o entendimento dos modelos, sendo semelhante ao modo com que o próprio autor irá se reportar em relação aos modelos.

As ideias de modelo científico de Ronald Giere e Nancy Cartwright são introduzidas de modo a sugerir que ambas concepções corroboram com a noção de Suppe de sistema abstrato. Este capítulo é o primeiro em que vemos uma longa explicação de como os modelos não são apenas projetos de máquinas nomológicas, à luz do trabalho de Cartwright, mas são, de fato, máquinas nomológicas abstratas. Embora Giere e Cartwright tenham visões muito contrastantes acerca do papel e do estatuto ontológico dos modelos, o autor recorre a ambos os autores para, aos poucos, montar sua própria concepção sobre estas estruturas. Além disso, o problema de reconhecimento dos modelos também é tratado nesta discussão. Ou seja, dada uma teoria, como saber quais modelos são pertencentes a ela? Em uma tentativa de fornecer uma resposta à pergunta, Dutra é levado a concordar com Giere que apenas quem conhece a teoria e trabalha com ela pode decidir isto (DUTRA, 2013, p.139), permitindo-nos inferir que os modelos são criados e difundidos de maneira coletiva pelos cientistas.

A ideia de modelos como mediadores é apresentada no capítulo seis, o qual é iniciado por uma breve revisão do trabalho de Morgan e Morrison. Em relação aos tópicos discutidos na obra das autoras, Dutra enfatiza quatro aspectos fundamentais sobre os modelos: sua construção; seu funcionamento; seu papel de representação e como podemos aprender com eles. A discussão da autonomia dos modelos científicos também é citada (e criticada!) pelo autor. A esse respeito, ele tenta pôr em xeque o modo sobre como Morgan e Morrison entendem o seu funcionamento como mediadores. À parte sua crítica, o autor não considera equivocada a abordagem das autoras. Ao contrário. Ele a considera uma das visões mais prolíficas e detalhadas em aspectos epistemológicos, embora incompleta. Para ele, as noções de modelo e teoria devem ser relacionadas, mas não no sentido de colocar uma noção em um estatuto de maior valor que a outra. Desta maneira, o autor ressalta que o trabalho das autoras corre o risco de "supervalorizar o estatuto dos modelos em detrimento da teoria" (DUTRA, 2013, p.185). Embora sejamos solidários a esta ideia, não encontramos este risco no trabalho de Morgan e Morrison. Ao contrário, é-nos claro que a meta destas autoras é a de equiparar o status dos modelos ao das teorias e de outras estruturas inerentes à prática científica, desconstruindo a concepção de que os modelos seriam meros aparatos subservientes à teoria. A esse respeito, Morrison enfatiza:

A implicação da nossa investigação é a de que os modelos não devam mais ser tratados como subordinados à teoria e aos dados na produção de conhecimento. Os modelos se juntam a instrumentos de medição, experimentos, teorias e dados como um dos ingredientes essenciais $^{1}$ na prática da Ciência (MORRISON, 1999, p. 36)

Na sequência do texto é discutida a relação entre modelos, simulações e experimentos imaginários. Para o autor, a contribuição de Cartwright no sentido de entendermos os modelos como projetos de máquinas nomológicas está ligada a experimentos imaginários e simulações. Esses recursos têm importância devido ao fato de que, com eles, podemos obter novo conhecimento sobre o mundo. Assim, Dutra menciona o caso de modelos digitais colocando em destaque duas questões predominantes: a primeira, relacionada ao número de variáveis envolvidas nos acontecimentos que desejamos estudar, como no caso dos fenômenos climáticos; a segunda, relacionada à energia necessária para reproduzir ou simular determinados fenômenos, como no caso dos fenômenos geológicos e astronômicos. Desta maneira, ao aceitarmos a simulação como forma de experimentação, podemos passar a considerar alguns domínios de conhecimento como ciências experimentais, como é o caso da astronomia.

1 Grifo nosso. 
No oitavo capítulo, a discussão gira em torno da natureza dos modelos científicos. Assim como já fora explicitado nos capítulos precedentes, o autor mantém sua posição de que os modelos científicos são entidades abstratas. Desta maneira, o caráter abstrato deles pode ser verificado ao compará-los com outras estruturas abstratas como as instituições. Uma posição que o autor sustenta é a de que as ciências humanas demonstram ser um campo mais fecundo para a utilização dos modelos que as ciências naturais. Isto ocorre, segundo Dutra, porque nas ciências humanas lida-se com diversos tipos de instituição em diferentes momentos. Além disso, o autor recorre à ontologia para explicar em que sentido podemos considerar que as entidades abstratas, entre elas as próprias instituições e modelos, são reais (embora não sejam concretas). Para ele, isto tem de ser feito de uma maneira que não multipliquemos entidades sem necessidade ou que não cometamos reificações indevidas.

Também é enfatizado pelo autor que os modelos que realmente importam nas ciências são os modelos abstratos por deterem um caráter autônomo, institucional e normativo. Assim, para discutir a relação entre diferentes tipos de modelos, o autor recorre à noção de cognição distribuída de Hutchins. Além disso, Araújo Dutra procura generalizar as ideias de Popper relativas à lógica situacional para quaisquer ciências, o que nos permitiria compreender que em todos os domínios científicos podemos encarar a atividade científica sempre como uma contextualização de máquinas nomológicas, isto é, a aplicação de modelos abstratos a situações concretas.

No décimo e último capítulo, Dutra aponta que todos os objetos de estudo das ciências humanas envolvem a ação de indivíduos por suas próprias vontades ou por meio de instituições. Neste sentido, enfatiza que tais ações de um indivíduo não podem resultar em uma situação social - a qual implica um caráter coletivo e institucional. Além disso, o autor aponta a questão da calibragem, ou seja, o problema de saber em que medida o entendimento de um evento social ou cultural depende do entendimento prévio de eventos psicológicos ou mentais, biológicos e de outros eventos sociais já estudados e bem caracterizados. Segundo Dutra, as concepções reducionistas tendem a eliminar um ou mais desses três aspectos e procuram calibrar seu estudo com base apenas em um ou outro deles. Nas seções seguintes, é feita uma discussão acerca de sistemas hierárquicos, das reificações indevidas e das falsas causas de eventos sociais. Para Dutra, a forma com que precisamos levar estas discussões a cabo consiste em termos uma concepção equilibrada da calibragem e Dutra o faz a partir da concepção que discute a lógica situacional de Popper. Finalmente, na última seção, o autor destaca o papel indispensável dos indivíduos nas instituições, mas chamando a atenção para o fato de que não necessariamente o que acontece nelas depende dos seres no sentido individual, psicológico ou biológico.

Tendo em vista a extensão e a riqueza bibliográfica contemplada no livro, escolheu-se manter o tom descritivo nesta resenha. De modo geral, as descrições encontradas no livro se mantêm fiel aos trabalhos que o autor se propôs a revisar e suas interpretações, às vezes controversas, constituem interessantes reflexões sobre o tema. A ideia de "mundos possíveis" é necessária ao entendimento do modelo como estrutura abstrata? Morgan e Morrison supervalorizam o estatuto dos modelos? A função dos modelos é realmente "mais clara e valorizada nas ciências humanas"? Independentemente de concordarmos ou não com essas posições, elas podem servir como ponto de partida para discussões enriquecedoras. Por este motivo, o livro é recomendado a todos que se interessem pelo tema dos modelos científicos, propiciando o debate de uma questão que há muito fora iniciada e, até então, permanece em aberto.

\section{Referências}

DUTRA, L. H. A. - Pragmática de modelos - natureza, estrutura e uso dos modelos científicos. São Paulo: Edições Loyola, 2013.

MORRISON, M. - Models as autonomous agents IN: MORGAN, M. MORRISON, M. (Eds.) Models as mediators perspectives on natural and social science. New York: Cambridge University Press, 1999. 